\title{
Could combat stress affect journalists' news reporting? A psychophysiological response
}

\author{
Autores \\ José Francisco Tornero-Aguilera, José Juan Robles-Pérez, Vicente Javier Clemente-Suárez
}

\begin{abstract}
Covering war conflicts may compromise the psychological and physical health of journalists because chronic exposure to these environments has been related to depression, memory dissociative processes, and post-traumatic stress disorder; however, acute effects have not been studied yet. Thus, a combat simulation was carried out replicating actual warfare scenarios, including personnel and equipment. Psychophysiological response, memory, and informationprocessing were analysed of 40 professional soldiers ( 21 males and 19 females) and 19 journalists (12 males and 7 females) with international experience in current conflict areas such as Afghanistan, Iraq, Bosnia and Herzegovina, and Kosovo, in relation to their experience of a combat intervention. A significant increase $(p<0.05)$ in metabolic, muscular, cardiovascular, and cortical and psychological anxiety response, as well as a decrease in memory accuracy directly after and 24 $\mathrm{h}$ and $72 \mathrm{~h}$ post-combat were found; these modifications were modulated by the nature of the stimulus. Journalists presented higher cognitive and memory impairment than soldiers, resulting in a press reporting of real events accuracy of only $27 \%$.
\end{abstract}

Palabras clave

Anxiety, Cortical arousal, Embedded journalism, Soldiers, Stress. 